\title{
Article
}

\section{Dramatic photoluminescence quenching in carbon dots induced by cyclic voltammetry}

Tian, Y, Li, L, Guo, X, Wójtowicz, A, Estevez, L, Krysmann, Marta and Kelarakis, Antonios

Available at http://clok.uclan.ac.uk/23813/

Tian, Y, Li, L, Guo, X, Wójtowicz, A, Estevez, L, Krysmann, Marta ORCID: 00000002-8036-4925 and Kelarakis, Antonios ORCID: 0000-0002-8112-5176 (2018) Dramatic photoluminescence quenching in carbon dots induced by cyclic voltammetry. Chemical Communications, 54 (65). pp. 9067-9070. ISSN 1359-7345

It is advisable to refer to the publisher's version if you intend to cite from the work. http://dx.doi.org/10.1039/c8cc03617a

For more information about UCLan's research in this area go to http://www.uclan.ac.uk/researchgroups/ and search for <name of research Group>.

For information about Research generally at UCLan please go to http://www.uclan.ac.uk/research/

All outputs in CLoK are protected by Intellectual Property Rights law, including Copyright law. Copyright, IPR and Moral Rights for the works on this site are retained by the individual authors and/or other copyright owners. Terms and conditions for use of this material are defined in the policies page.

\section{CLoK}

Central Lancashire online Knowledge www.clok.uclan.ac.uk

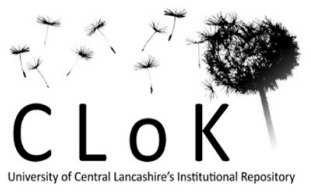




\title{
Journal Name
}

\section{ARTICLE}

\section{Dramatic photoluminescence quenching in carbon dots induced by cyclic voltammetry}

Received 00th January 20xx, Accepted 00th January 20xx

DOI: $10.1039 / x 0 x \times 00000 x$

www.rsc.org/

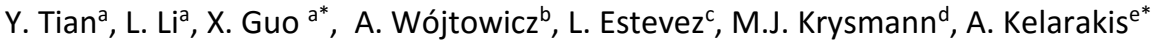

The study focuses on the structural rearrengements and the photoluminescent behavior of pyrolytically derived carbon dots when subjected to a series of cyclic voltammetry sweeps. Although the electrical signals involved are not pronounced, multiple electrochemical cycling results in a progressive suppression of the photoluminescence, so that after 42 sweeps the intensity is reduced by one order of magnitude. At the same time, the fluorescence component stemming from the organic fluorophores is blue-shifted, while the contribution of the carbogenic cores is red-shifted. XPS and FTIR spectra reveal that the voltammetric field induces an extensive formation of $\mathrm{C}-\mathrm{O}$ and $\mathrm{C}=\mathrm{O}$ at the expences of the $\mathrm{C}=\mathrm{C}$ bonds. Our findings indicate a close relationship between the electrochemical response and the structure of $\mathrm{C}$-dots and, thus, have direct implications on the development of $\mathrm{C}$-dots based electroluminescent materials, electrochemical sensors and solar cells.

Highly photoluminescent (PL) carbogenic nanoparticles, otherwise known as carbon dots or C-dots, are synthesized during the decomposition of carbon superstructures such as graphene $^{1}$, carbon fibers ${ }^{2}$, carbon nanototubes ${ }^{3}$, carbon black ${ }^{4}$ or during the pyrolytic treatment of carbon-rich precursors, including abundant materials such as natural products ${ }^{5}$, crude biomass ${ }^{6}$, etc. Typically, C-dots are composed of carbon, hydrogen and oxygen, while heteroatom doping (sulphur, nitrogen, boron, phosphorus, etc.) is common ${ }^{7-9}$. In principle, Cdots exhibit characteristic excitation wavelength-dependent emission with high quantum yields and remarkable resistance to photobleaching ${ }^{7-9}$.

Moreover, there is growing evidence to suggest that C-dots show low toxicity against humans and the environment and, thus, are often referred to as the environmental benign alternatives to heavy metal based quantum dots ${ }^{10}$. Owing to this unique combination of promising properties, C-dots are systematically explored in optoelectronics ${ }^{11}$, solar photovoltaics ${ }^{12}$, bio-imaging ${ }^{13}$, cancer therapy ${ }^{13}$, photocatalysis ${ }^{14}$ and chemical sensing ${ }^{15}$. In addition, interest lies on the development of a new generation of

\footnotetext{
a. East China University of Science and Technology (ECUST), Shanghai, China,guoxuhong@ecust.edu.cn, tel.021-64253491

b. Chemistry Department, Jagiellonian University in Krakow, Poland

c. Pacific Northwest National Laboratory, Richland, WA, USA

d. School of Pharmacy and Biosciences, University of Central Lancashire, Preston PR12HE, U.K.

e. School of Physical Sciences and Computing, University of Central Lancashire, Preston PR12HE, U.K. email: akelarakis@uclan.ac.uk, tel:004417724172

f. Electronic Supplementary Information (ESI) available: Detailed Experimental Section, FTIR data, XPS spectra, XPS data analysis, controlled tests using citrazinic acid and $\mathrm{C}$-dots derived at $300^{\circ} \mathrm{C}$.
}

antimicrobials ${ }^{16}$ forensic materials ${ }^{17,18}$ and nanothermometers ${ }^{19}$.

Although, the PL mechanism is not fully understood, four contributions have been recognised associated to edge and surface defects, quantum confinement of $\mathrm{sp}^{2}$ islands, crosslink enhanced emission and the presence of organic chromophores, respectively ${ }^{20}$. The persisting challenge in elucidating the $\mathrm{PL}$ mechanism in large arises from the fact that different synthetic strategies generate C-dots with varying sizes and size distributions, shapes, heteroatom doping, surface defects, functionalities, carbonization and graphitization degrees. To that end, electrochemistry has been employed to synthesize well-defined C-dots via oxidative cleavage of the sacrifice carbon electrodes, to accurately tune their size and, thereby, their band gap as well as the oxidation state of the surface functional groups ${ }^{21}$.

In this study we demonstrate for the first time that the application of a rather moderate electrochemical field can dramatically reduce the emissive intensity of $\mathrm{C}$-dots, providing insights on the underlying photoactive mechanism. In particular, we focus on C-dots prepared by the pyrolytic treatment of a mixture of ethanolamine/citric acid at $230{ }^{\circ} \mathrm{C}$. We have previously reported that the PL spectra of this type of C-dots can be analysed into two distinct contributions; one bright blue, excitation wavelength-independent contribution stemming from the presence of molecular fluorophores $\left(\mathrm{I}_{\mathrm{f}}\right)$ and the excitation wavelength-dependent mode arising from the carbogenic cores $\left(I_{c}\right)^{22}$. It is now well established that citrazinic acid-based molecular fluorophores $\left(\lambda_{\max }=450 \mathrm{~nm}\right)$ are dominant at low reaction temperatures, but they are progressively consumed at higher temperatures where they undergo further crosslinking and carbonization towards the formation of the carbogenic cores with lower quantum yields ${ }^{22-}$ 25 . 
(a)
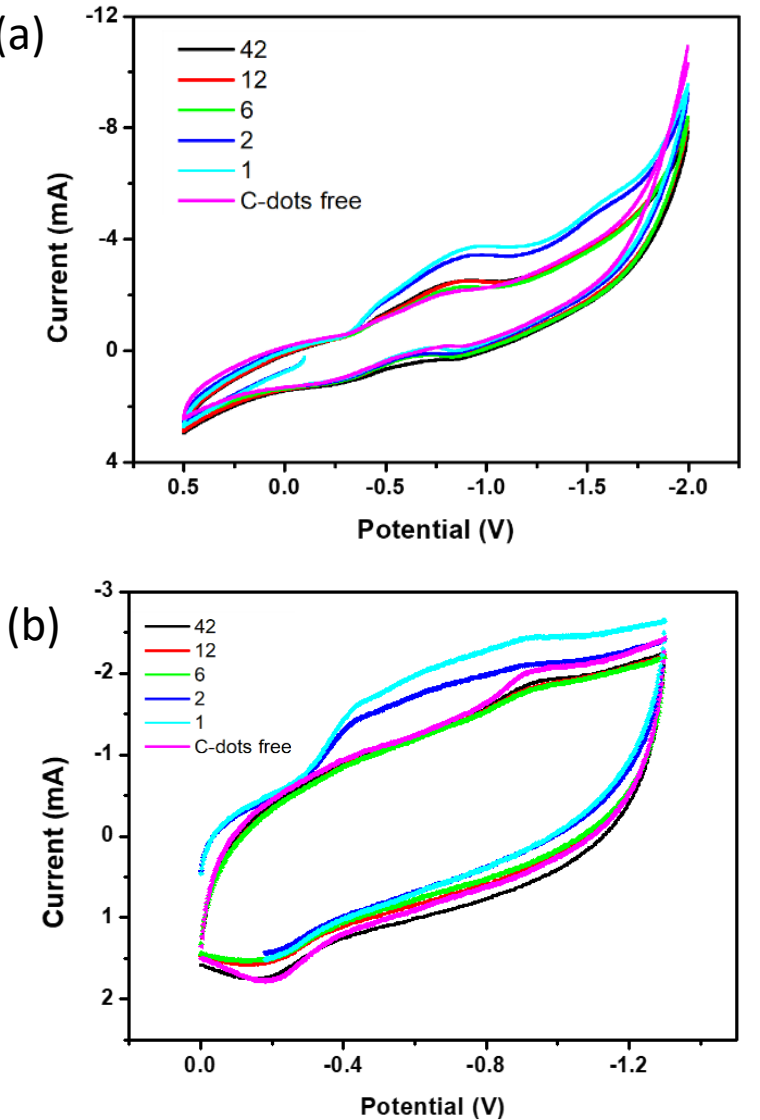

Figure 1. Multiple-cycle voltammograms of aqueous dispersions containing $0.1 \mathrm{mg} / \mathrm{ml} \mathrm{C}$-dots (for clarity only cycles 1,2,6,12,42 are shown) within the operational potential range: a) $-2.0 \mathrm{~V}$ to $0.5 \mathrm{~V}$ and b) $-1.3 \vee$ to $0.0 \mathrm{~V}$. The corresponding C-dots free solutions are also included for comparison.

A series of successive cyclic voltammograms (CV) of C-dots aqueous dispersions (for clarity only cycles 1,2,6,12,42 are shown) within the operational potential range $-2.0 \mathrm{~V}$ to $0.5 \mathrm{~V}$ is displayed in Figure 1a. The first sweep shows a reduction peak at $-970 \mathrm{mV}$, but upon further cycling this value gradually shifts towards less negative potentials approaching $-870 \mathrm{mV}$ at the $6^{\text {th }}$ cycle (the oxidation peaks appear at $-868 \mathrm{mV}$ for all cycles). At the same time, the corresponding cathodic current is progressively reduced, revealing the occurrence of partially irreversible transfer reactions. Interestingly, when a narrower potential window is applied (Figure 1b), the currents involved are much weaker, indicating that the dominant redox mechanism is activated only at harsh potentials. Multiple-CV profiles with features resembling those seen in Figure 1a, have been reported for graphene oxides prepared using permanganate oxidants and have been attributed to cyclic conjugated redox couples containing ketone and carboxylic groups $^{26}$. Likewise, single-cycle voltammographs of C-dots (electrode-immobilized or in the dispersed state) have been explained in terms of charge transfer reactions of peripheral units with a quinone-like structure ${ }^{27-29}$. For reference, it is noted that among the electro-reducible oxygen-bearing groups, peroxyl and epoxyl groups behave irreversibly, while isolated carbonyl groups are reduced reversibly but only at harsh potentials in excess of $-2.0 \mathrm{~V}^{26}$.

(a)

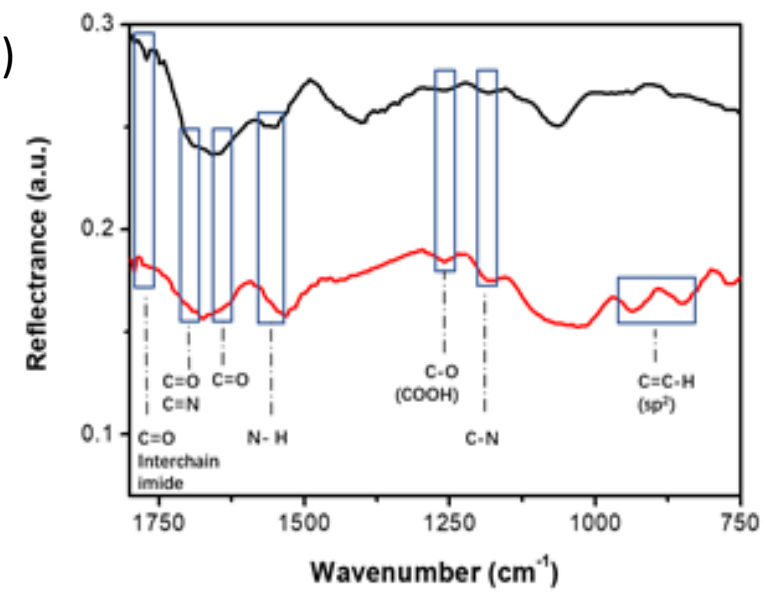

(b)

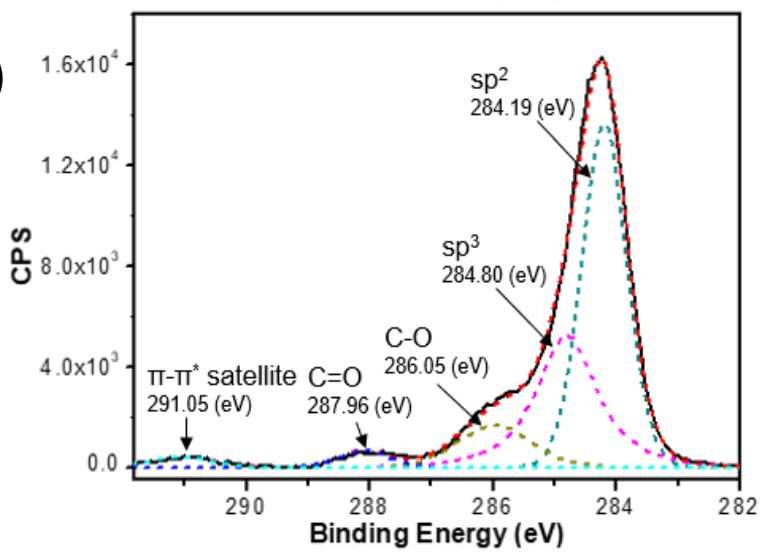

(c)

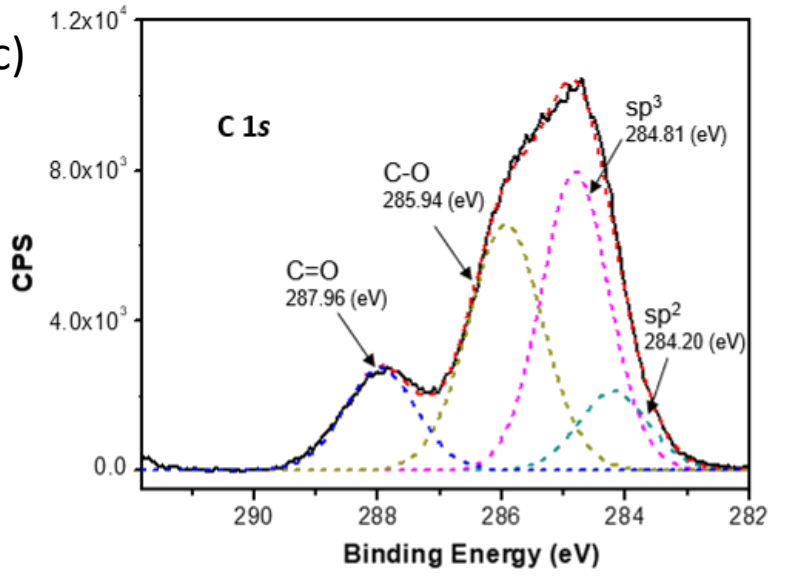

Figure 2. (a) FTIR spectra of C-dots prior (lower red line) and after (upper black line) the application of $42 \mathrm{CV}$ scans. C1s XPS spectra of Cdots prior (b) and after (c) the application of $42 \mathrm{CV}$ scans. Solid lines refer to the data collected, while the dashed lines refer to the fitted curves.

Experimental evidence suggests that the application of the electrical field results in pronounced structural rearrangements in C-dots. The FTIR spectra plotted in Figure 2a (ESI Table 1 summarises the peak positions of the functional groups) show that the peaks centred at 935 and $850 \mathrm{~cm}^{-1}$, both corresponding 
to bending vibration of the $\mathrm{C}=\mathrm{C}-\mathrm{H}$ bond from the $\mathrm{sp}^{2}$ carbon $^{30}$, are dominant prior the electrochemical treatment, but are essentially absent after the $\mathrm{CV}$ scans. This observation points to pronounced rearrangements and breakage of the $\mathrm{C}=\mathrm{C}$ bonds. Deconvolution of the C1s XPS spectrum of the C-dots prior the electrochemical treatment reveals the presence of $52 \% \mathrm{sp}^{2}$ carbon (accompanied by a well-defined $\pi-\pi^{*}$ satellite peak) compared to only $11.40 \%$ (the $\pi-\pi^{*}$ satellite peak becomes undetectable) after the application of $42 \mathrm{CV}$ cycles. At the same time, the electrochemical treatment enhances the percentage of C-O from $9.07 \%$ to $35.47 \%$ and the percentage of C=O from $2.45 \%$ to $14.24 \%$. In other words, XPS data confirms the extensive breakage of the $\mathrm{C}=\mathrm{C}$ bonds and the formation of $\mathrm{C}-\mathrm{O}$ and $\mathrm{C}=\mathrm{O}$. (Survey XPS, N1s and O1s spectra prior and after the electrochemical treatment are presented in ESI Figures 1 and 2, respectively, while ESI Tables 2 and 3 summarise the results of XPS analysis.)

Despite those transformations, the morphology and the size of the nanoparticles are not affected by the electrical field. TEM imaging prior and after the CV scans (Figure $3 a$ and $b$, respectively) indicates the presence of spherical nanoparticles with narrow size distribution and average diameter close to 21 $\mathrm{nm}$ in agreement with previous studies ${ }^{22}$. (a)

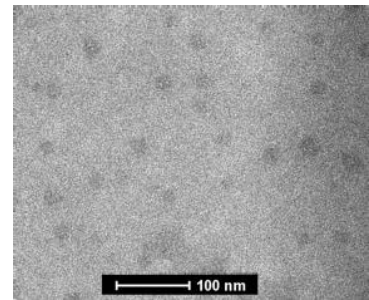

(b)

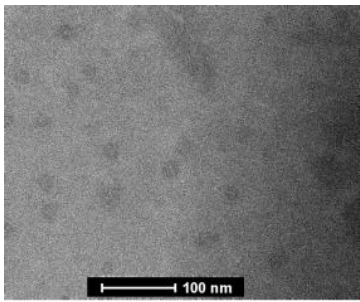

Figure 3. TEM images of C-dots prior (a) and after (b) the application of 42 CV scans.

PL spectroscopy provides further evidence on the structural and electronic rearrangements occurring during the electrochemical treatment. As seen in Figure 4, both the PL intensities $I_{c}$ and $I_{f}$ progressively drop, exhibiting more than one order of magnitude quenching after $42 \mathrm{CV}$ cycles. Compared to the electrochemically untreated C-dots (black squares in Figure 4), electrooxidized C-dots show a higher content of oxygenated defects that act as emissive traps and a lower degree of conjugation in their carbogenic core (Figure 2) that leads to weaker PL emissions.

At the same time, a striking difference between the two contributions is observed in Figure 4 given that $I_{f}$ is blue-shifted (Figure 4a), while $I_{c}$ is red-shifted (Figure $4 b$ ). In agreement with the trends observed for $I_{c}$, oxidation by means of strong oxidants (e.g. $\mathrm{KMnO}_{4}, \mathrm{KIO}_{4}$ ) generates carbonyl and epoxy moieties at the expenses of hydroxyl groups, causing a 10 fold $\mathrm{PL}$ quenching and a $70 \mathrm{~nm}$ red shift ${ }^{31}$. However, in contrast to the behaviour observed in this study, treatment with strong oxidants does not alter the $\mathrm{sp}^{2}$ content of the C-dots ${ }^{31}$.

Interestingly, simultaneous hydroxyl group generation and $\mathrm{sp}^{2}$ content enhancement upon a photochemical reduction pathway result in pronounced PL improvements, but the effect has been demonstrated only for graphene quantum dots ${ }^{32}$. To the best of our knowledge, this is the first study that reports such a dramatic electrochemical response in C-dots along with the parallel action of a blue-shifted and a red-shifted PL contribution. It should be emphasised that chemical treatments convert strongly emissive surface reduced C-dots ("on" state) to their weakly emissive counterparts ("off" state) 31,32 , while electrochemical methods afford access to a number of intermediate oxidation states (Figure 4), allowing fine-tuning of the structure and, thereby, the PL properties.
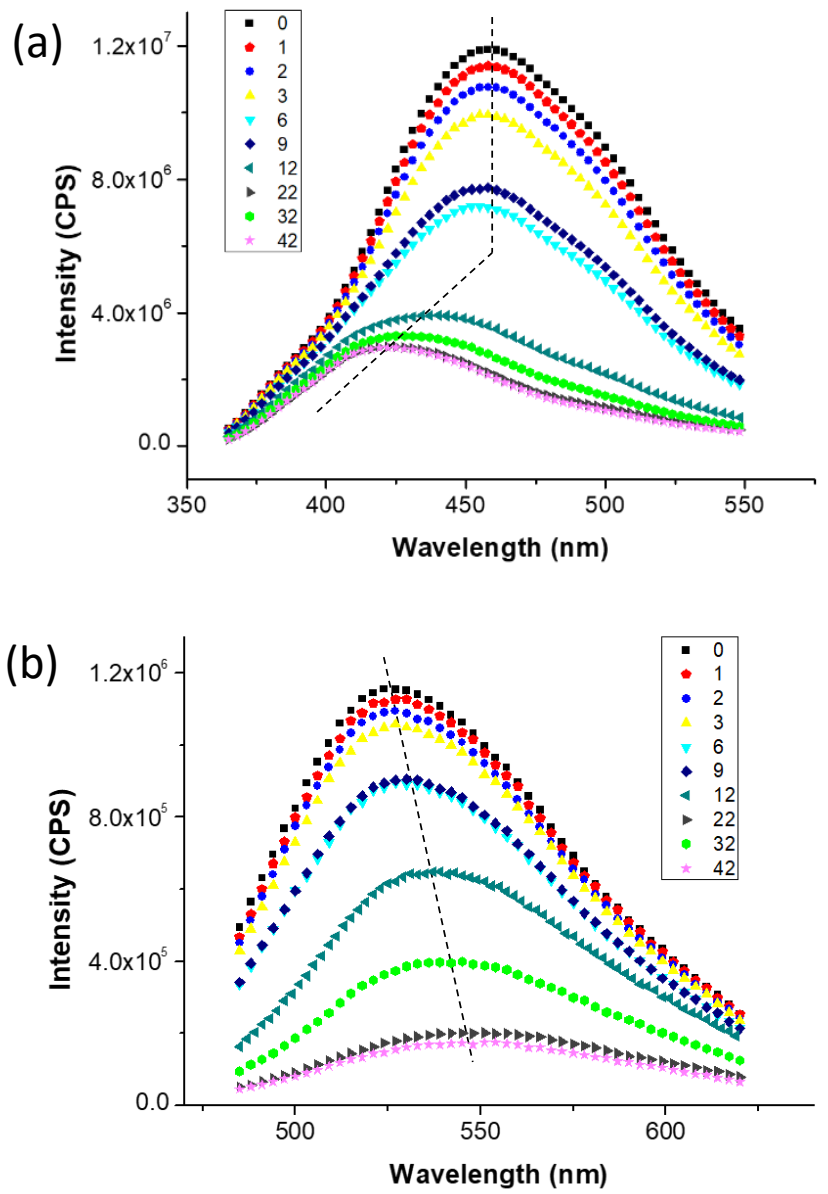

Figure 4. PL emission spectra of $10 \mu \mathrm{g} / \mathrm{ml}$ aqueous dispersions of $\mathrm{C}$-dots that have been subjected to $0,1,2,3,6,9,12,22,32,42$ cyclic voltammetry cycles at excitation wavelengths: (a) $380 \mathrm{~nm}$ and (b) $470 \mathrm{~nm}$. The black dotted lines are guide to the eye.

To gain further insights, we performed three control tests. First, citrazinic acid subjected to identical electrochemical treatment was found to exhibit 10\% PL quenching (E.S.I. Figure 3). Second, the C-dots were subjected to the narrower potential window described in Figure $1 \mathrm{~b}$ and showed $28 \%$ quenching after $42 \mathrm{CV}$ cycles (E.S.I. Figure 4). Third, we considered C-dots pyrolytically derived from EA/CA at $300{ }^{\circ} \mathrm{C}$ (rather than at $230{ }^{\circ} \mathrm{C}$ described above). It is well-established that higher reaction temperatures ${ }^{23}$ and longer reaction times ${ }^{33}$ favour the synthesis of highly cross-linked carbogenic cores comprising 
predominantly aromatic hydrocarbons. TEM imaging (ESI Figure $5 a)$ indicate the presence of spherical particles with average diameter $8 \mathrm{~nm}$, in agreement with previous studies ${ }^{22}$. As seen in ESI Figure $5 b$, the multiple-voltammetry profiles only show minimal currents accompanied by a very limited PL quenching, e.g. $2 \%$ reduction after 42 cycles (ESI Figure $5 c$ ).

In a previous study, it was shown that C-dots derived by electrochemical etching of carbon fibbers, when subjected to $2.5 \mathrm{~V}$ exhibit surface oxidation and their emission spectra are red-shifted by $45 \mathrm{~nm}$, but their quantum yield remains essentially unaltered ${ }^{34}$.

Those observations suggest that the electrochemical response of C-dots critically depends upon their structure and chemical nature, with those pyrolytically derived at intermediate temperatures $\left(230{ }^{\circ} \mathrm{C}\right)$ to be more prone to structural rearrangements and extensive quenching.

\section{Conclusions}

We elucidate an electrochemically activated quenching mechanism that is dominant in C-dots derived pyrolytically at intermediate temperatures. In particular, we demonstrate here that application of a moderate voltammetric field induces pronounced structural and electronic rearrangements within the surface (generation of oxygenated defects) as well as the interior of the carbogenic cores (lower degree of conjugation) giving rise to dramatic PL quenching. Our findings suggest that the electrochemical response of C-dots largely depends on the nature of the carbogenic core and this behaviour might play a pronounced role in key-applications related to electroluminescent materials, electrochemical sensors and solar cells.

\section{Conflicts of interest}

There are no conflicts to declare.

\section{Acknowledgements}

Y.T. acknowledges financial support from China Scholarship Council to work in Preston within the framework "Newton Fund PhD Placement Grant". A.W. acknowledges financial support from Erasmus PLus to work in Preston.

\section{References}

1 D. Pan, J. Zhang, Z. Li, and M. Wu, Adv. Mater., 2010, 22, 73438.

2 J. Peng, W. Gao, B.K. Gupta, Z. Liu, R. Romero-Aburto, L. Ge, L. Song, L.-B. Alemany, X. Zhan, G. Gao, S.-A. Vithayathil, B.A. Kaipparettu, A.-A. Marti, T. Hayashi, J. Zhu, and P.-M. Ajayan, Nano Lett., 2011, 12, 844-849.

3 D.B. Shinde, and V.-K. Pillai, Chem. - A Eur. J., 2012, 18, 12522 12528.

4 Y. Dong, C. Chen, X. Zheng, L. Gao, Z. Cui, H. Yang, C. Guo, Y. Chi, and C.-M. Li, J. Mater. Chem., 2012, 22, 8764.

5 X. Zhang, M. Jiang, N. Niu, Z. Chen, S. Li, S. Liu, and J. Li, ChemSusChem., 2018,11,11-24.
6 M.-J. Krysmann, A. Kelarakis, and E.-P. Giannelis, Green Chem., 2012, 14, 3141-3145.

7 L. Lingling, W. Gehui, Y. Guohai, P. Juan, Z. Jianwei, and Z. Junjie, Nanoscale, 2013 ,5, 4015-4139.

8 S.-Y. Lim, W. Shen, and Z. Gao, Chem. Soc. Rev., 2014, 44, 362381.

9 A. Kelarakis, Curr. Opin. Colloid Interface Sci., 2015, 20, 354361.

10 H. Tao, K. Yang, Z. Ma, J. Wan, Y. Zhang, Z. Kang, and Z. Liu, Small, 2012, 8, 281-290.

11 F. Yuan, S. Li, Z. Fan, X. Meng, L. Fan, and S. Yang, Nano Today, 2016, 11, 565-586.

12 J.-B. Essner, and G.-A. Baker, Environ. Sci. Nano., 2017, 4, 1216-1263.

13 K. Hola, Y. Zhang, Y. Wang, E.-P. Giannelis, R. Zboril, and A.-L. Rogach, Nano Today., 2014, 9, 590-603.

14 H. Li, X. He, Z. Kang, H. Huang, Y. Liu, J. Liu, et al., Angew Chem. Int. Ed., 2010, 49, 4430-4434.

15 X. Sun, and Y. Lei, Trends in Analytical Chemistry, 2017,89,163180.

16 J. Yang, X. Zhang, Y.-H. Ma, G. Gao, X. Chen, H.-R. Jia, Y.-H. Li, Z. Chen, and F.-G. Wu, Appl. Mater. Interfaces, 2016, 8 (47), 32170-32181.

17 D. Fernandes, M.-J. Krysmann, and A. Kelarakis, Chem. Commun., 2015, 51, 4902-4905.

18 D. Fernandes, M.-J. Krysmann, and A. Kelarakis, Chem. Commun., 2016, 52, 3-5.

19 Y. Yang, W. Kong, H. Li, J. Liu, M. Yang, H. Huang, Y. Liu, Z. Wang, Z. Wang, T.-K. Sham, J. Zhong, C. Wang, Z. Liu, S.-T. Lee, and Z. Kang, ACS Appl. Mater. Interfaces, 2015, 7 (49), 2732427330.

20 S. Zhu, Y. Song, X. Zhao, J. Shao, J. Zhang, and B. Yang, Nano Res., 2015, 8, 355-381.

21 B.-P. Qi, L. Bao, Z.-L. Zhang, and D.-W. Pang, ACS Appl. Mater. Interfaces, 2016, 8 (42), 28372-28382.

22 M.-J. Krysmann, A. Kelarakis, P. Dallas, and E.-P. Giannelis, J. Am. Chem. Soc., 2012, 134, 747-750.

23 Y. Song, Z. Shoujun, Z. Shitong, F. Yu, W. Li, Z. Xiaohuan, and Y. Bai, J. Mater. Chem. C., 2015, 3, 5976-5984.

24 S. Zhua, X. Zhao, Y. Song, S. Lua, and B.Yanga, Nanotoday, 2016, 11, 128-132.

25 S. Lei, Y. Jianhai, Z. Haibo, C. Yongmei, Y. Shengchun, W. Chao, H. Zeng, O. Yoshihito, and Q. Zhang, Nanoscale, 2016, 8, 14374-14378.

26 A.-Y.-S. Eng, A. Ambrosi, C.-K. Chua, et al., Chemistry-A European Journal, 2013, 19(38): 12673-12683.

27 L. Tian, D. Ghosh, W. Chen, S. Pradhan, X. Chang, and S. Chen, Chem. Mater., 2009, 21, 2803-2809.

28 C.-S. Lim, K. Hola, A. Ambrosi, R. Zboril, and M. Pumera, Electrochemistry Communications, 2015, 52, 75-79.

29 B.-P. Qi, H. Hu, L. Bao, et al., Nanoscale, 2015, 7(14), 59695973.

$30 \mathrm{~J}$. Dilag, H. Kobus, and Y. Yu, et al., Polymer International, 2015, 64(7), 884-891.

31 H. Zheng, Q. Wang, Y. Long, H. Zhang, X. Huang, and R. Zhu, Chem. Commun., 2011, 47, 10650-10652.

32 H. Sun, L. Wu, N. Gao, J. Ren and X. Qu ACS Appl. Mater. Interfaces 2013, 5, 1174-1179

33 F. Ehrat, S. Bhattacharyya, J. Schneider, A. Löf, R. Wyrwich, A. L. Rogach, J. K. Stolarczyk, A. S. Urban, J. Feldmann Nanoletters 2017,17,7710-7716

34 L. Bao, Z. Zhang, Z. Tian , L. Zhang, C. Liu , Y. Lin ,B. Qi , D. Pang Adv. Mater., 2011, 23, 5801-5806. 